\title{
Percepções de estudantes em saúde e sua relação com o projeto politico pedagógico escolar
}

\author{
Perception of students about health and their relationship with \\ political-pedagogic project
}

Loreanne Dos Santos Silva ${ }^{1}$

Vanderlei Folmer ${ }^{2}$

Simone Lara ${ }^{3}$

\section{Resumo}

A escola ocupa um lugar significativo no desenvolvimento de atividades de Educação e Saúde, entretanto não deve ser mera reprodutora de discursos sobre saúde. Com base na relevância desse tema, o objetivo do estudo foi investigar a percepção de estudantes sobre saúde e possiveis relações com o Projeto Político Pedagógico (PPP) escolar. Esse estudo incluiu estudantes do $9^{\circ}$ ano do Ensino Fundamental de três escolas públicas de um município no interior do Rio Grande do Sul, Brasil, sendo uma localizada na área rural e duas na área urbana (sendo, uma na periferia e outra no centro do município). Para a coleta de dados utilizou-se um Questionário para os estudantes e a Análise do PPP. Como resultados, apesar de as escolas preverem a abordagem da temática saúde em seu PPP, através de documentos como a Base Nacional Comum Curricular (BNCC) ou dos Planos de Estudos da rede municipal de ensino, as percepções dos escolares sobre essa temática ainda são limitadas. Os mesmos referem os temas de "Higiene/Auto-cuidado" e "Aprendizagem

\footnotetext{
${ }^{1}$ Mestranda do PPG: Educação em Ciências: quimica da vida e saúde, da Universidade Federal do Pampa UNIPAMPA, campus Uruguaiana.

2 Mestre em Educação em Ciências: Química da Vida e Saúde pela Universidade Federal do Rio Grande do Sul e doutor em Ciências Biológicas (Bioquímica Toxicológica) pela Universidade Federal de Santa Maria, docente do curso de Fisioterapia, de Ciências da natureza, e do PPG:Educação em Ciências: Química da Vida e Saúde, da Universidade Federal do Pampa - Campus Uruguaiana.

3 Doutora em educação em ciências: quimica da vida e saúde, mestre em fisiologia humana, docente do curso de Fisioterapia e do PPG: Educação em Ciências: quimica da vida e saúde, da Universidade Federal do Pampa - UNIPAMPA, campus Uruguaiana.

Interfaces da Educ., Paranaíba, v.11, n.31, p. 501 - 524, 2020
}

ISSN 2177-7691 
Percepções de estudantes em saúde...

sobre doenças/prevenção de doenças" como os mais abordados no contexto escolar. Assim, reforçamos a necessidade de fomentar ações de ES, para que essa abordagem se torne mais efetiva no ambiente escolar.

Palavras-chave: Educação e Saúde. Saúde na escola. Projeto Político Pedagógico escolar.

\section{Abstract}

The school occupies a significant place in the development of Education and Health activities, however it should not be mere reproducer of discourses about health. Based on the relevance of this theme, the aim of the study was to investigate students' perceptions of health and possible relationships with the school's Political Pedagogical Project (PPP). This study included 9th grade students from three public schools in a city in the interior of Rio Grande do Sul, Brasil, one located in the rural area and two in the urban area (one in the periphery and the other in the center of the city). For data collection, a Student Questionnaire and PPP analysis were used. As a result, although schools approach health in their PPP, through documents such as the National Common Core Curriculum (NCCC) or the curriculum of the municipal school system, the students' perceptions about this theme are still limited. They refer to "Hygiene/Self-care" and "Learning about diseases/disease prevention" as the most themes addressed in the school context. Thus, we reinforce the need to foster higher education actions so that this approach becomes more effective in the school environment.

Keywords: Education and Health. Health at school. School Pedagogical Political Project.

\section{Introdução}

Alves et al. (2018) entendem Educação e Saúde como a formação de atitudes e valores desenvolvidos na escola com o objetivo de promover nos alunos a adoção de atitudes favoráveis à saúde. Sobrinho et al. (2017) acrescentam que essa formação deve considerar o desenvolvimento integral Interfaces da Educ., Paranaíba, v. 11, n.31, p. 501 - 524, 2020 
do escolar, não limitando-se apenas no fornecimento de informações. Para estes autores a escola deve prover ao aluno a capacidade de analisar, avaliar informações e escolher o seu comportamento.

A escola pode ser considerada um espaço privilegiado na planificação de ações de promoção da saúde, uma vez que desempenha um papel fundamental na formação de valores, hábitos e estilos de vida (ALVES et al., 2018). Nascimento e Schetinger (2016) consideram a capacitação por meio da informação um exemplo de ação promotora de saúde, e vêem a informação como uma das bases para a tomada de decisão. Contudo, Barbi e Neto (2017) defendem que a escola não deve ser uma mera reprodutora de discursos sobre orientações em saúde ou percebida apenas como local fisico onde é realizada a assistência à saúde. A escola deva ser articuladora e problematizadora das diferentes realidades, contextualizando-as.

A escola ocupa um lugar significativo no desenvolvimento de atividades de Educação e Saúde. Para tanto, é fundamental que a Educação e Saúde esteja presente em todos os aspectos da vida escolar dos estudantes e seja uma prática contínua dentro e fora do ambiente escolar. Essas atividades proporcionam a construção da consciência crítica dos estudantes em relação à importância da aquisição de hábitos saudáveis, incentivando os estudantes a se tornarem sujeitos ativos do seu próprio cuidado (VIERO et al., 2015; SOBRINHO et al., 2017; BARBI e NETO, 2017)

A abordagem em saúde no contexto escolar é relevante ao passo que está prevista na legislação, incluindo os Parâmetros Curriculares Nacionais (PCN) e a Base Nacional Comum Curricular (BNCC). Os primeiros abordam o tema saúde como um dos objetivos gerais a serem alcançados no final de cada ciclo do Ensino Fundamental. Ainda, preveem que os estudantes possam conhecer e cuidar de seu corpo, valorizar e adotar hábitos de vida saudáveis, de forma que tenham atitudes e escolhas responsáveis em relação à saúde.

Os PCN trazem em seu bloco temático "Ser humano e Saúde" fatores que compreendem a saúde como fator físico, psíquico e social. O documento resguarda que o estado de saúde dos indivíduos seja decorrente da satisfação ou não de necessidades biológicas, afetivas, sociais e culturais (BRASIL, 1998). Já na BNCC, as questões de saúde estão mais evidentes no componente Interfaces da Educ., Paranaíba, v.11, n.31, p. 501 - 524, 2020 
Percepções de estudantes em saúde...

curricular da disciplina de Educação Física, expressando a relação entre a boa saúde vinculada à prática de atividades físicas, bem como na disciplina de Ciências (BRASIL, 2016).

Além da abordagem em saúde estar prevista nos documentos legais supracitados, é relevante que o Projeto Político Pedagógico (PPP) escolar integre essa temática, considerando o contexto da escola, para que o trabalho em saúde envolva a comunidade escolar. Para Mendes (2017), o objetivo do PPP é organizar o trabalho da escola, sejam atividades administrativas, pedagógicas e/ou didáticas. Segundo Gadotti (1994), o PPP é um projeto que implica, acima de tudo, um certo referencial teórico-filosófico e político. Ele não fica, contudo, no referencial, ele implica em estratégias e propostas práticas de ação.

Em relação à construção do PPP, Weyh et al. (2019) consideram que deve ser realizado de forma coletiva, participativa e colaborativa. Além disso, O PPP deve envolver todos os segmentos da comunidade escolar e do seu entorno. Nesta perspectiva, Mendes (2017) afirma que o PPP representa um dos instrumentos consolidadores de uma gestão democrática, portanto deve ser um documento elaborado por todos da comunidade escolar.

Cabe salientar, a necessidade de conhecer a cultura prévia dos estudantes ao iniciar o estudo, conhecer o que eles pensam e a bagagem de conhecimentos que trazem. Assim, necessitamos definir alguns conceitos utilizados em pesquisas educacionais, como o conceito de "concepção" e de “percepção". Matos e Jardilino (2016) entendem o termo concepção como "construção de conceitos", a concepção está ligada a um conceito, é uma rede complexa que constrói idéias, conceitos e explicações. Já o termo "percepção", segundos os autores, envolve as sensações, a consciência e representação dos objetos externos para o indivíduo.

Diante disto, para pensar em estratégias mais efetivas de educação e saúde no ambiente escolar, é relevante conhecer a percepção dos estudantes sobre saúde. Também, é de grande importância analisar se tais percepções podem estar associadas com o que é previsto no PPP da escola, em relação à abordagem com saúde. Sendo assim, o objetivo do estudo foi investigar a 
percepção dos estudantes sobre questões de saúde, as temáticas de saúde trabalhadas no contexto escolar e possíveis relações com o PPP escolar.

\section{Metodologia}

Trata-se de um estudo transversal, descritivo, qualitativo e quantitativo, no qual foram incluídos estudantes do $9^{\circ}$ ano do ensino fundamental de três escolas públicas, de um município no interior do Rio Grande do Sul, Brasil, sendo uma localizada na zona rural, outra na zona urbana (região central do município), e outra na zona urbana (região periférica do município), selecionadas por conveniência (figura 01).

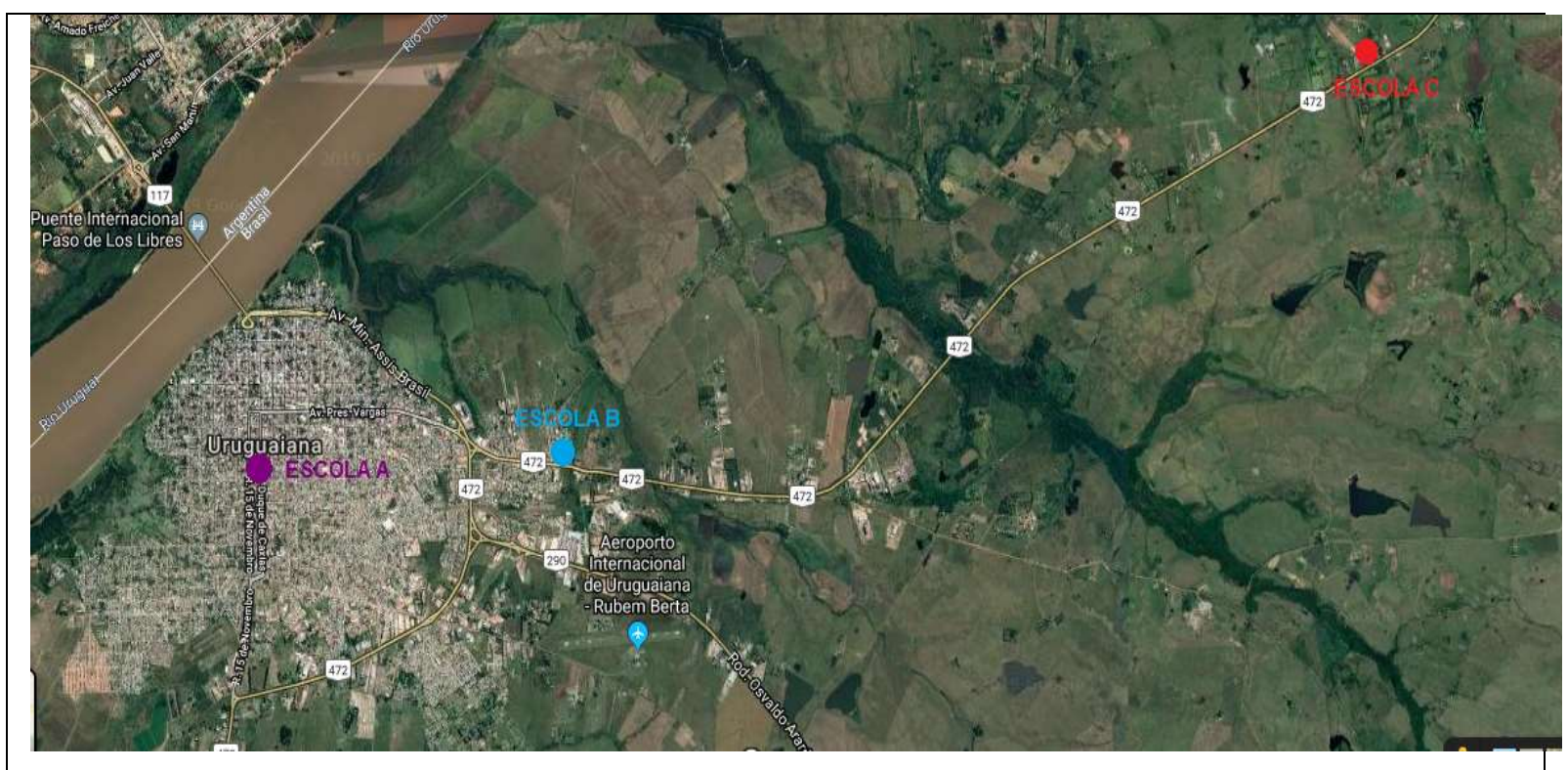

Figura 01. Localização geográfica das escolas A, B e C. Fonte: Google Maps, 2018

A escola A localiza-se na região central do município. Fundada em 1976, é composta por 35 professores, 14 funcionários e 02 estagiários (auxiliares pedagógicos), atendendo aproximadamente 453 alunos, do $1^{\circ}$ ao $9^{\circ}$ ano do Ensino Fundamental. O Índice de Desenvolvimento da Educação Básica (IDEB) da escola A em 2017 foi de 6,3.

A escola B situa-se na área urbana do município, na zona leste do mesmo, à periferia da cidade, às proximidades da BR472. Fundada em 1960 e ampliada em 2008, seu quadro de pessoal é constituído por 53 professores e 23 funcionários, atendendo a aproximadamente 665 alunos. É composta por turmas da pré-escola (etapas 5 e 6) até o $9^{\circ}$ ano do Ensino Fundamental. O IDEB da escola foi de 5,3 em 2015. Em 2017, o exame aplicado pelo INEP 
Percepções de estudantes em saúde...

nessa instituição foi realizado somente com estudantes do $9^{\circ}$ ano, e, desta forma, pela falta da média de desempenho de alguns alunos no exame, não foi possivel calcular o IDEB.

A escola $\mathrm{C}$ encontra-se localizada na zona rural do municipio, distante cerca de $15 \mathrm{~km}$ do centro da cidade, composta por 22 professores e 09 funcionários. O IDEB escolar foi avaliado somente no ano de 2017 (com nota $4,8)$, visto o número de alunos não ser suficiente para a avaliação nos anos anteriores. Fundada no ano de 2010, a escola possui cerca de 120 alunos, atende escolares da Pré-escola (Etapa 5 e 6) até o $9^{\circ}$ ano do Ensino Fundamental.

Nas escolas urbanas, foi sorteada a turma do $9^{\circ}$ ano a ser selecionada para o estudo, já na escola rural não houve necessidade de sorteio tendo em vista que só havia uma turma de alunos de $9^{\circ}$ ano. A realização do estudo com turmas do $9^{\circ}$ ano do Ensino Fundamental justifica-se pelo fato destes alunos já terem passado por todo o ensino fundamental, onde encontramos na BNCC, a previsão da abordagem de diferentes conteúdos sobre saúde em cada ano escolar.

Os estudantes assinaram um termo de assentimento e seus responsáveis, um termo de consentimento livre e esclarecido, explicando os objetivos e o propósito da pesquisa. A proposta foi aprovada pelo Comitê de Ética institucional, sob o número 3.138.702.

Para a coleta de dados foram utilizadas as seguintes ferramentas metodológicas:

- Questionário aplicado aos estudantes: A fim de investigar a percepção dos estudantes sobre saúde, bem como a abordagem dessa temática na escola, os mesmos responderam às seguintes questões abertas: "o que é saúde para você?", “quais os temas sobre saúde você lembra ter aprendido na escola?” e “em quais disciplinas você lembra ter estudado temas sobre saúde?”. O uso desse questionário teve como base o estudo de Moreira e Dupas (2003), no qual foi utilizado um roteiro para entrevista do tipo semi-estruturada, com o intuito de identificar as percepções prévias sobre saúde de escolares.

- Análise do Projeto Politico Pedagógico (PPP) escolar: foi realizada a análise do PPP de cada escola envolvida na pesquisa, com o propósito de Interfaces da Educ., Paranaíba, v.11, n.31, p. 501 - 524, 2020 
conhecer o que é previsto em seus documentos acerca do tema Saúde. Conforme Longhi e Bento (2006), a construção do PPP constitui-se em um documento que reflete a realidade escolar e tem como objetivo melhorar a prática educativa e visualizar novas possibilidades e transformações da realidade.

Para a análise dos dados qualitativos, foi utilizada a análise de Bardin (2006), que é caracterizada por um conjunto de instrumentos metodológicos que se aplicam a discursos (conteúdos e continentes) extremamente diversificados. Após a categorização dos dados qualitativos, foi realizada uma análise de frequências, para determinar o percentual de relatos em cada categoria.

Ainda, as percepções de saúde dos estudantes foram apresentadas através de nuvens de palavras. Esta ferramenta compreende uma forma de visualização de dados linguísticos, que mostra a frequência com que as palavras aparecem em um dado contexto (Mcnaught e Lam, 2010). A mesma utiliza tamanhos e fontes de letras diferentes de acordo com as ocorrências das palavras no texto analisado, gerando uma imagem que apresenta um conjunto de palavras, coletadas do corpo do texto e agregadas de acordo com sua frequência, sendo que a que mais aparece é alocada no centro da imagem e as demais em seu entorno, de modo decrescente (Dias et al., 2014).

\section{Resultados e discussão}

Para apresentação dos dados, optamos por organizá-los sob a forma de dois tópicos: Aspectos gerais sobre o Projeto Político Pedagógico (PPP) e relações entre a análise do PPP e as percepções dos escolares sobre saúde.

Aspectos gerais sobre o Projeto Politico Pedagógico escolar

Apresentaremos a seguir as características gerais do PPP escolar de cada instituição analisada.

\section{Escola A}

O objetivo dessa escola é promover uma educação que favoreça a construção do conhecimento, proporcionando condições, para que o sujeito Interfaces da Educ., Paranaíba, v.11, n.31, p. 501 - 524, 2020 
Percepções de estudantes em saúde...

possa desenvolver-se de forma crítica, criativa, com comprometimento social assumindo valores para tornar-se cidadão autônomo e responsável. O currículo é aberto às demandas da sociedade e os conteúdos fazem referência aos Planos de Estudos da rede municipal de ensino, devendo ter real significado e valorizar vivências e contexto do aluno.

Em relação às temáticas sobre saúde, a análise dos planos de ciências traz o eixo "Ser Humano e Saúde", cujo foco aborda a constituição biológica dos seres humanos e o funcionamento do corpo humano. Esse eixo inclui, além do funcionamento dos sistemas orgânicos do corpo humano, questões de saúde ambiental, como a contaminação da água, do solo e ar, bem como temas sobre sexualidade, reprodução humana e genética. O plano de estudos da disciplina de Educação Física para os anos finais do ensino fundamental inclui jogos, esportes, danças, ginásticas, lutas, práticas corporais de aventura urbanas ( $6^{\circ}$ e $7^{\circ}$ anos), práticas corporais de aventura na natureza ( $8^{\circ}$ e $9^{\circ}$ ano) práticas corporais, saúde e sociedade (para todos os anos finais).

Dentre as principais habilidades referidas, direcionado ao $6^{\circ}$ e $7^{\circ}$ ano, encontram-se: conhecer as noções básicas de saúde; desenvolver hábitos saudáveis; reconhecer e aplicar os conhecimentos sobre a hidratação durante a atividade física; identificar e analisar os efeitos da atividade física sobre o organismo e saúde; compreender a atividade física na promoção da saúde e na qualidade de vida. Já para o $8^{\circ}$ e $9^{\circ}$ ano, as habilidades incluem: compreender que a saúde é produzida nas relações com o meio físico, econômico e sociocultural, identificando fatores de risco à saúde pessoal e coletiva presente no meio em que vive e entender a prática regular de exercícios físicos e sua relação com a saúde na complexidade de fatores individuais e coletivos.

A metodologia da escola visa buscar recursos e estratégias adequadas que garantam o ensino de qualidade através do conhecimento prévio do aluno, do desenvolvimento de suas habilidades e competências básicas, da construção de saberes, da elaboração, construção e resolução de problemas e da reflexão das práticas educativas.

Escola B

Interfaces da Educ., Paranaíba, v.11, n.31, p. 501 - 524, 2020 
A instituição tem como objetivo central a promoção da educação integral da criança e jovem através de um processo de ensino de qualidade, partindo de suas experiências pessoais e considerando-o agente ativo e crítico neste processo, investindo em seu desenvolvimento e em suas potencialidades. A escola atende muitos alunos que vivem em condições precárias, algumas famílias vivem em um contexto sem muita motivação para os filhos, o que a escola considera como fator indispensável à alfabetização letrada. Para tanto, nesse quadro de carência extrema em que vivem muitos alunos, os mesmos vêem a escola como um ponto de referência para alimentação e saúde, condições de higiene e de sobrevivência.

A carência afetiva, segundo a escola, é um fator que causa prejuízo na formação integral do ser humano. A escola assume tarefas muito além da alfabetização, sendo a principal delas, tornar cidadão aqueles que sentem fortemente a força da exclusão social. A escola não descreve em seu PPP, de que forma abordará os temas de saúde, não fazendo referência, por exemplo, aos Planos de Estudos da rede municipal de ensino, nem aos temas transversais conforme os Parâmetros Curriculares Nacionais (PCN), e nem a Base Nacional Comum Curricular (BNCC). Apenas reitera que os conteúdos serão abordados conforme as demandas, levando em conta especialmente a realidade dos educandos.

\section{Escola C}

A maioria dos estudantes da escola C são filhos de trabalhadores rurais e residem em granjas, estâncias ou pequenas propriedades. Devido ao deslocamento de grande número de estudantes residentes no meio rural para escolas da zona urbana acabar gerando diversos problemas sociais, como a infrequência, drogas, gravidez precoce e outras situações de desajuste social, surgiu a necessidade da ampliação da escola, possibilitando aos estudantes dar continuidade aos estudos do Ensino Fundamental no meio rural.

O objetivo geral da escola é proporcionar a formação básica do cidadão, mediante quatro as aspectos: 1) o desenvolvimento da capacidade de aprender, tendo como meios básicos o pleno desenvolvimento da leitura, da escrita e do raciocínio lógico matemático; 2) a compreensão do ambiente Interfaces da Educ., Paranaíba, v.11, n.31, p. 501 - 524, 2020 
Percepções de estudantes em saúde...

natural e social, do sistema político, da tecnologia, das artes e dos valores em que se fundamenta a sociedade; 3) o desenvolvimento da capacidade de aprendizagem, tendo em vista a aquisição de conhecimento e habilidades e a formação de atitudes e valores; 4) o fortalecimento dos vínculos de família, dos laços de solidariedade humana e de tolerância recíproca em que se assenta a vida social.

Em relação à metodologia de ensino, a escola prioriza a construção do conhecimento, considera os conteúdos como um meio para o desenvolvimento de habilidades e baseia-se com o que está previsto na BNCC para esta etapa de ensino. Nesse sentido, A BNCC prevê o tema saúde no currículo da disciplina de Educação Física nos anos finais do ensino fundamental na unidade temática "Ginásticas" e dentre as habilidades propostas encontra-se "Promover a saúde" e "Contribuir para a melhoria das condições de vida, saúde, bem-estar e cuidado consigo mesmo".

A temática saúde também é prevista pela BNCC no currículo da disciplina de ciências no $7^{\circ}$ ano do ensino fundamental, na unidade temática "Vida e Evolução", com o intuito de desenvolver a habilidade de interpretar as condições de saúde das comunidades, analisar e comparar indicadores de saúde e os resultados de políticas públicas destinadas à saúde, bem como aspectos relacionados à vacinação.

Ainda em relação a esse eixo, é proposto para o $8^{\circ}$ ano trabalhar com Mecanismos reprodutivos e Sexualidade, envolvendo aspectos relativos à sexualidade humana, bem como a prevenção da gravidez precoce e de Doenças Sexualmente Transmissiveis (DST). Para o $9^{\circ}$ ano, no eixo "Matéria e energia" é previsto trabalhar Radiações e suas aplicações na saúde.

O quadro 1 apresenta características dos PPP das escolas analisadas, o que permite analisar e fazer uma comparação entre as mesmas. Os PPP das três escolas foram redigidos em data aproximadas, entre 2016 e 2017. É possivel perceber que as escolas A e B utilizam a mesma metodologia, a sócio interacionista, enquanto na escola $\mathrm{C}$ a metodologia é baseada na construção do conhecimento. Como perfil do educando, todas as escolas citam o aluno como sujeito crítico. 
Em relação aos conteúdos, a escola A relata o embasamento nos Planos de Estudos da rede municipal de ensino e a escola $\mathrm{C}$ baseia-se no que a BNCC prevê para cada etapa de ensino. Somente a escola B não apresenta referências para fundamentação dos conteúdos a serem trabalhados por seus professores. Cabe ressaltar que, embora somente a escola A cite os Planos de Estudos da rede municipal de ensino em seu PPP, na prática, todas as escolas municipais são reguladas por esses planos, inclusive os professores participam de sua construção nas reuniões de área.

O tema saúde, de forma geral, é abordado na escola A, através dos Planos de Estudos da rede municipal de ensino nas disciplinas de Educação Física e Ciências, e na escola C, por intermédio da BNCC no currículo da disciplina de Educação Física e Ciências. Em relação a temáticas específicas em saúde, relacionadas à promoção de saúde, como alimentação saudável e prática de atividade física, percebemos que são abordadas de forma mais evidente apenas na escola A.

Quadro 1. Características dos PPP das escolas analisadas

\begin{tabular}{|c|c|c|c|}
\hline $\begin{array}{c}\text { Variáveis } \\
\text { analisadas }\end{array}$ & $\begin{array}{c}\text { Escola } A \\
\text { Urbana central }\end{array}$ & $\begin{array}{c}\text { Escola B } \\
\text { Urbana } \\
\text { periférica }\end{array}$ & $\begin{array}{c}\text { Escola C } \\
\text { Rural }\end{array}$ \\
\hline Ano da redação & 2017 & 2016 & 2016 \\
\hline $\begin{array}{l}\text { Metodologia de } \\
\text { ensino }\end{array}$ & $\begin{array}{c}\text { sócio } \\
\text { interacionista }\end{array}$ & $\begin{array}{c}\text { sócio } \\
\text { interacionista }\end{array}$ & $\begin{array}{l}\text { construção do } \\
\text { conhecimento }\end{array}$ \\
\hline $\begin{array}{l}\text { Perfil do } \\
\text { educador }\end{array}$ & $\begin{array}{l}\text { transmissor de } \\
\text { valores, zelo e } \\
\text { respeito, com } \\
\text { participação ativa } \\
\text { na formação do } \\
\text { cidadão }\end{array}$ & $\begin{array}{c}\text { mediador entre o } \\
\text { conteúdo e o } \\
\text { conhecimento. }\end{array}$ & $\begin{array}{c}\text { engajado no } \\
\text { processo de } \\
\text { transformação } \\
\text { social, com } \\
\text { prática } \\
\text { humanizadora e } \\
\text { transformadora. }\end{array}$ \\
\hline $\begin{array}{l}\text { Perfil do } \\
\text { educando }\end{array}$ & $\begin{array}{l}\text { ser critico e } \\
\text { questionador, }\end{array}$ & $\begin{array}{l}\text { sujeito em } \\
\text { transformação, }\end{array}$ & $\begin{array}{l}\text { ser pensante, } \\
\text { transformador, }\end{array}$ \\
\hline
\end{tabular}


Percepções de estudantes em saúde...

\begin{tabular}{|c|c|c|c|}
\hline & $\begin{array}{c}\text { construtor de } \\
\text { saberes e fazeres }\end{array}$ & $\begin{array}{c}\text { crítico e } \\
\text { dinâmico, } \\
\text { reconhece } \\
\text { direitos e cumpre } \\
\text { deveres }\end{array}$ & $\begin{array}{c}\text { critico, capaz de } \\
\text { interagir com o } \\
\text { meio }\end{array}$ \\
\hline Conteúdos & $\begin{array}{c}\text { referência aos } \\
\text { Planos de Estudos } \\
\text { da rede municipal } \\
\text { de ensino }\end{array}$ & $\begin{array}{l}\text { não faz } \\
\text { referências }\end{array}$ & $\begin{array}{c}\text { referência a } \\
\text { Base Nacional } \\
\text { Comum } \\
\text { Curricular }\end{array}$ \\
\hline $\begin{array}{l}\text { Abordagem em } \\
\text { saúde }\end{array}$ & $\begin{array}{l}\text { Planos de Estudos } \\
\text { da rede municipal } \\
\text { de ensino nas } \\
\text { disciplinas de } \\
\text { Educação Física e } \\
\text { Ciências }\end{array}$ & $\begin{array}{c}\text { não faz } \\
\text { referências }\end{array}$ & $\begin{array}{c}\text { Currículo da } \\
\text { disciplina de } \\
\text { Educação Física } \\
\text { e Ciências na } \\
\text { Base Nacional } \\
\text { Comum } \\
\text { Curricular }\end{array}$ \\
\hline $\begin{array}{c}\text { Temas em } \\
\text { saúde: } \\
\text { Alimentação } \\
\text { saudável e } \\
\text { Atividade Física }\end{array}$ & $\begin{array}{c}\text { referência nos } \\
\text { Planos de Estudos } \\
\text { da rede municipal } \\
\text { de ensino }\end{array}$ & $\begin{array}{l}\text { não faz } \\
\text { referências }\end{array}$ & $\begin{array}{l}\text { não faz } \\
\text { referências }\end{array}$ \\
\hline
\end{tabular}

Fonte: Os autores, 2018

Percepções dos escolares sobre saúde e possiveis relações com o PPP escolar

Foram incluídos 26 alunos da escola A, 23 da escola B e 12 da escola C, de 14 e 16 nos, de ambos os sexos. A fim de conhecer as percepções dos escolares sobre saúde, foi questionado aos mesmos: "O que é saúde para você?”. Por meio de nuvens de palavras, podemos evidenciar diferenças importantes quanto às percepções dos estudantes em cada escola.

Os estudantes da escola A (Figura 2) relacionaram o conceito de saúde ao bem-estar e "sentir-se bem", e apresentaram um modelo de conceito mais ampliado de saúde, quando referiram que a saúde não é somente "ausência de doenças". Além disso, os alunos também descreveram a questão mais Interfaces da Educ., Paranaíba, v.11, n.31, p. 501 - 524, 2020 
biológica do modelo de saúde, quando incluíram percepções relacionadas ao "funcionamento do corpo humano".

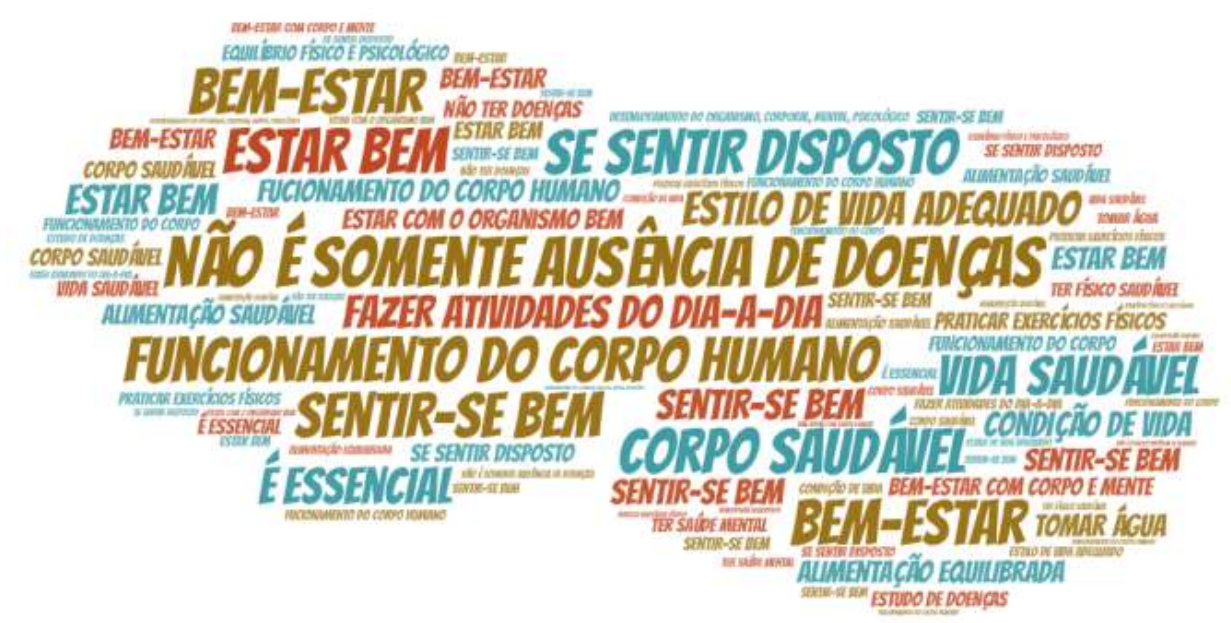

Figura 2. Nuvem de palavras sobre a percepção dos escolares sobre saúde - Escola A. Fonte: os autores, 2018.

Nas percepções dos escolares da escola B (Figura 3), também foi destacado o bem-estar, porém, o autocuidado foi enfatizado, como "se cuidar" e "cuidar da nossa vida".

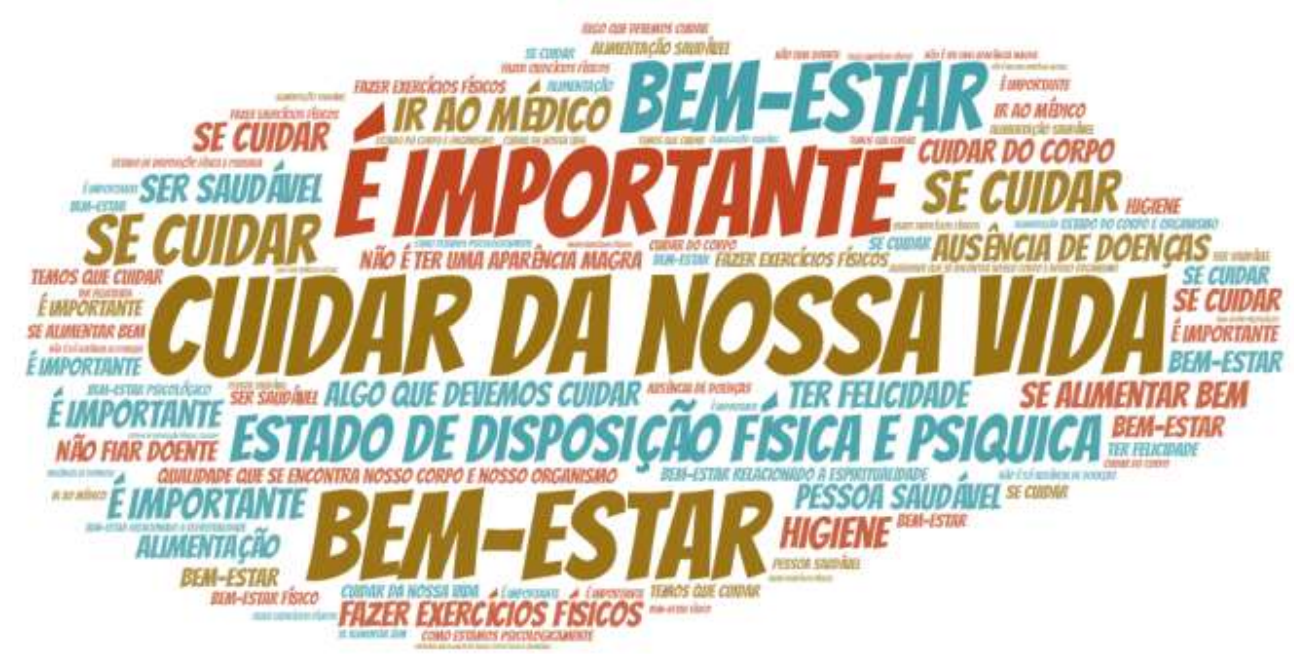

Figura 3. Nuvem de palavras sobre a percepção dos escolares sobre saúde - Escola B. Fonte: os autores, 2018. 
Percepções de estudantes em saúde...

Já na escola C (Figura 4), os escolares deram maior ênfase para a relação da saúde com a higiene e alimentação saudável, destacando que saúde "é tudo" e que "sem ela não vivemos".

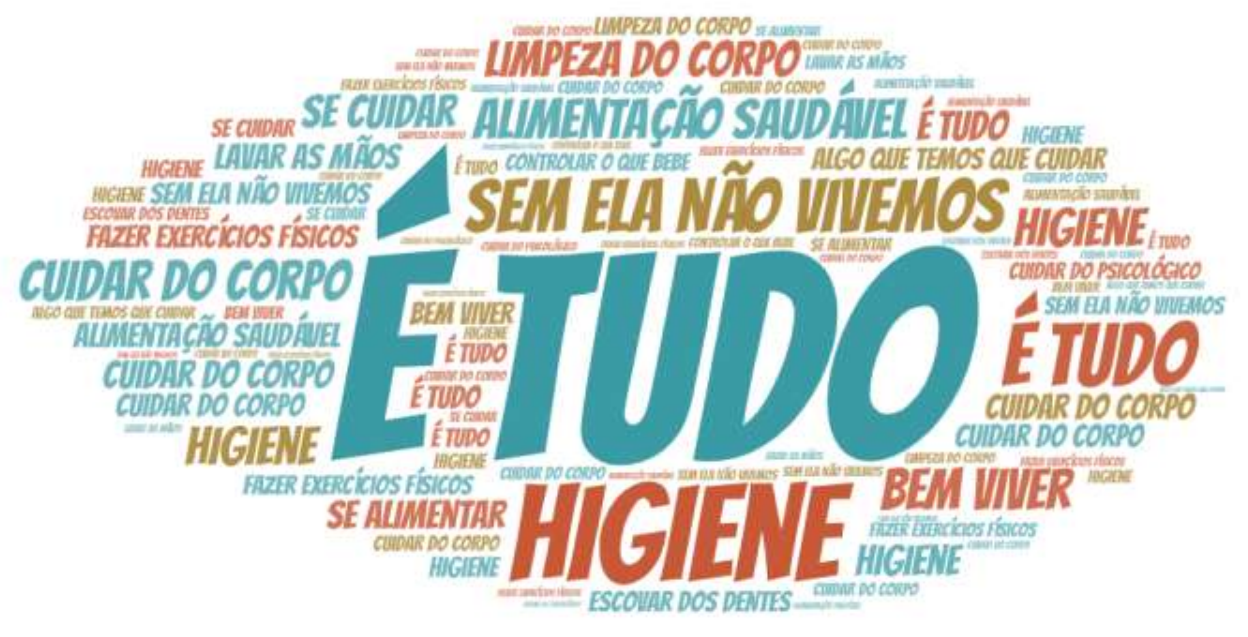

Figura 4. Nuvem de palavras sobre a percepção dos escolares sobre saúde - Escola C. Fonte: os autores, 2018.

Com base nesses resultados, podemos ressaltar diferenças importantes entre as percepções dos escolares sobre saúde. Os estudantes da escola A apresentaram um conceito mais holístico de saúde, quando inseriram que a mesma "não é somente a ausência de doenças". Esse conceito ampliado de saúde está mais próximo do colocado pela Organização Mundial da Saúde (OMS), que conceitua saúde como um estado de completo bem-estar físico, mental e social e não apenas pela ausência de doenças ou enfermidades (OMS, 1946).

Por outro lado, percebemos que os estudantes da escola B e C ainda apresentaram um conceito reducionista de saúde, relacionado basicamente ao auto-cuidado e questões de higiene. Similar ao apresentado, outros estudos também mostraram uma percepção superficial dos escolares sobre aspectos de saúde, ou seja, a saúde não vista de uma forma integral, mas a partir de uma visão associada ao auto-cuidado, a higiene, ao "não estar doente". No estudo de Moreira e Dupas (2003), a causa de saúde considerada mais importante foi "tomar cuidado consigo mesmo". A pesquisa compreendeu o significado que crianças de 07 e 12 anos atribuem à saúde e à doença e 
constatou que as primeiras correlações dos escolares com saúde estão associadas aos cuidados com a alimentação, a higiene e a prática de exercícios físicos.

Outro estudo (Macedo e Conceição, 2015) realizado com adolescentes na faixa etária de 13 a 19 anos, identificou a questão de saúde sob uma visão unidirecional, como não ter nenhuma doença e estar unicamente relacionado ao cuidado corporal. Os autores destacam que a idéia de estar saudável para os adolescentes pesquisados significa não sentir nada, como se o estado de completo bem-estar fosse recebido de forma passiva e apenas no sentido do corpo. Portanto, os autores concluíram que em sua pesquisa foi excluída a idéia de saúde integral proposta pela OMS (1946).

No presente estudo, nos questionamentos sobre temáticas em saúde aprendidas no contexto escolar (tabela 1), percebemos que as mais abordadas, nas três instituições foram "Higiene/Auto-cuidado" e "Aprendizagem sobre doenças/prevenção de doenças". Cabe ressaltar, que tanto a escola A quanto a escola C tratam com maior incidência a questão da prevenção de doenças e não a questão da promoção da saúde como prevê a BNCC. Quanto aos temas em saúde de maior frequência, na escola A foi apontado o "Funcionamento dos sistemas do corpo humano" e a "Aprendizagem sobre doenças/prevenção de doenças". Já na escola B, destacaram-se os temas relacionados a "Questões sobre alimentação" e a "Orientações sexuais/prevenção de DST". E na escola C, apareceram a "Higiene/Auto-cuidado" e a "Aprendizagem sobre doenças/prevenção de doenças".

Tabela 01. Percepção dos alunos sobre os temas de saúde abordados na escola

\begin{tabular}{lcccc}
\hline \multicolumn{1}{c}{ DISCIPLINA } & $\begin{array}{c}\text { ESCOLA A } \\
\text { N (\%) }\end{array}$ & $\begin{array}{c}\text { ESCOLA B } \\
\text { N (\%) }\end{array}$ & $\begin{array}{c}\text { ESCOLA C } \\
\text { N (\%) }\end{array}$ & $\begin{array}{c}\text { TOTAL } \\
\text { N (\%) }\end{array}$ \\
\hline $\begin{array}{l}\text { Questões sobre } \\
\text { alimentação }\end{array}$ & $10(38,46 \%)$ & $10(43,47 \%)$ & $4(33,33 \%)$ & $24(38,42 \%)$ \\
$\begin{array}{l}\text { Questões associadas à } \\
\text { atividade }\end{array}$ & $3(11,53 \%)$ & $8(34,78 \%)$ & $3(25 \%)$ & $14(23,77 \%)$ \\
\end{tabular}


física/exercícios

físicos/esportes
Drogas
$4(15,38 \%)$
0
0
$4(5,12 \%)$

Higiene/Auto-cuidado

$3(11,53 \%) \quad 8(34,78 \%)$

$9(75 \%) \quad 20(40,44 \%)$

Saúde/Saúde Mental/

Questões

$6(23,07 \%) \quad 3(13,04 \%) \quad 1(8,33 \%) \quad 10(14,81 \%)$

emocionais / psicológicas

Orientações

sexuais/prevenção de

$3(11,53 \%) \quad 10(43,47 \%) \quad 1(8,33 \%) \quad 14(21,11 \%)$

DST

Importância da

água/hidratação

$2(7,69 \%) \quad 2(8,69 \%) \quad 0 \quad 4(5,46 \%)$

Funcionamento dos

sistemas do corpo

$19(73,07 \%) \quad 7(30,43 \%)$

$0 \quad 26(34,5 \%)$

humano

Aprendizagem sobre

doenças / prevenção de $13(50 \%) \quad 4(17,39 \%) \quad 8(66,66 \%) 25(44,68 \%)$

doenças

Não responderam

$2(7,69 \%)$

$2(16,66 \%)$

$4(8,11 \%)$

Fonte: os autores, 2018

Buscando relacionar as percepções dos escolares ao previsto no PPP, percebe-se que a escola A aborda os Planos de Estudos da rede municipal, e, em seus planos de Ciências, tratam-se temáticas sobre constituição biológica do corpo humano e seu funcionamento. Desta forma, entendemos que se justifica o destaque dado nas respostas dos alunos ao tema "Funcionamento dos sistemas do corpo humano". Ademais, nos planos de Educação Física também são previstas temáticas relacionadas ao funcionamento do corpo humano como sistemas, regulação do movimento do corpo humano e função cardiorrespiratória e muscular. Neste plano, também são discorridos fatores 
que afetam o processo saúde-doença, enfatizando a incidência de respostas relacionadas ao tema "Aprendizagem sobre doenças/prevenção de doenças".

Acredita-se que a abordagem do tema "Questões sobre alimentação", destacados na escola $\mathrm{B}$, deve-se à realidade socioeconômica e condição de vulnerabilidade social em que vivem muitos estudantes desta escola. Ainda, evidencia-se o fato desses estudantes verem a escola como ponto de referência em relação a questões relacionadas à alimentação e saúde. Outro dado relevante dessa instituição é a abordagem da prevenção de Doenças Sexualmente Transmissiveis (DST) e orientações sexuais, que também pode ser justificada pelo contexto da vulnerabilidade social dos alunos. Acredita-se que os professores desta escola se preocupam com temas urgentes ao abordarem a temática saúde, a fim de evitar a gravidez na adolescência e prevenir as DST.

Ainda que não esteja previsto no PPP da escola os documentos como os PCN e a BNCC, a escola considera importante abordar, no contexto escolar, questões urgentes, conforme a comunidade escolar no qual estão inseridos. Essa questão está em consonância com o previsto nos PCN, no qual os temas transversais correspondem a questões urgentes para a sociedade brasileira (BRASIL, 1998). Vale ressaltar, que a escola B não descreve em seu PPP de que forma abordará temas relacionados à saúde, contudo, percebe-se que tais conteúdos são abordados conforme a realidade e as demandas de seus alunos.

A escola C apresenta o tema saúde em seu PPP com referências na BNCC. Nesse aspecto, percebemos que, embora esse documento preveja a abordagem do tema "Promover a saúde", presente no currículo de Educação Física, evidenciamos que os alunos não apresentam tal percepção. Ainda assim, os alunos apontam a "prevenção de doenças" como um dos temas mais trabalhados em sala de aula.

Por outro lado, percebemos algumas questões respondidas pelos alunos, em consonância com o que prevê a BNCC. Dentre essas, a questão do autocuidado é encontrada na habilidade "Contribuir para a melhoria das condições de vida, saúde, bem-estar e cuidado consigo mesmo", o que justifica o tema "Higiene/Auto-cuidado" ter grande incidência de respostas. Adicionalmente, 
Percepções de estudantes em saúde...

no currículo de Ciências, é tratada a vacinação, que também pode ser considerada como auto-cuidado e prevenção de doenças.

Com base nos resultados encontrados, há necessidade da abordagem da promoção da saúde nas escolas pesquisadas, visto o enfoque dado pelos escolares na doença, em especial na escola A e C. Entende-se que não se tem claro as diferenças entre promoção da saúde e prevenção de doenças. Merece destaque, no entanto, que o conceito de promoção da saúde, previsto pela OMS, está relacionado ao processo de capacitação dos indivíduos para melhorar o controle de sua saúde (WHO, 2010). Já o conceito de prevenção da saúde refere-se à orientação para evitar o surgimento de doenças específicas, evitando sua incidência e prevalência (CZERESNIA, 2009).

Embora a BNCC proponha a promoção da saúde como uma habilidade a ser trabalhada, percebe-se uma visão limitada da saúde, que engloba as questões biológicas e funcionamento do corpo associado ao modelo patogênico. Prochnow, Souza e Farias (2016) reiteram que informações envolvendo o funcionamento do corpo humano, doenças e higiene não têm sido suficientes para a transformação de hábitos e mudanças de comportamento. Para os autores uma abordagem mais significativa da saúde atrelada à qualidade de vida, possibilita esclarecer os fatores sociais envolvidos na promoção da saúde, gerando percepção da necessidade de conscientização quanto ao direito à melhoria na qualidade de vida.

$\mathrm{Na}$ tabela 2, os estudantes, independente da escola, responderam que as disciplinas de Ciências e de Educação Física, respectivamente, foram aquelas em que eles lembram, com mais frequência, ter abordado as questões de saúde na escola. Ciências foi a disciplina que apresentou maior destaque, correspondendo a $97,26 \%$ das respostas.

Tabela 02. Temas de saúde abordados na escola

\begin{tabular}{lllll}
\hline \multirow{2}{*}{ DISCIPLINA } & ESCOLA A & ESCOLA B & ESCOLA & TOTAL \\
& N (\%) & N (\%) & C & N (\%) \\
& & & $\mathbf{N}(\%)$ & \\
\hline Ciências & $25(96,15 \%)$ & $22(95,65 \%)$ & $12(100 \%)$ & $59(97,26 \%)$
\end{tabular}




$\begin{array}{lllll}\text { Educação Física } & 7(26,92 \%) & 13(56,52 \%) & 3(25 \%) & 23(36,14 \%) \\ \text { Ensino Religioso } & 4(15,38 \%) & 2(8,69 \%) & 1(8,33 \%) & 7(10,8 \%) \\ \text { Português } & 3(11,53 \%) & 10(43,47 \%) & 2(16,66 \%) & 15(23,89 \%)\end{array}$

Fonte: os autores, 2018

Monteiro (2012) corrobora com esses achados, por colocar que, no âmbito da escolarização formal, cabe tradicionalmente às disciplinas de Ciências (Ensino Fundamental), Biologia (Ensino Médio) e Educação Física o desenvolvimento das propostas e conteúdos relacionados à saúde. O autor ainda destaca que os professores de tais disciplinas se intitulam como os agentes de saúde dentro da escola.

Entretanto, os PCN consideram saúde um tema transversal, e, portanto, deve perpassar por todas as áreas de conhecimento. O documento também entende que somente com a participação das diversas áreas do saber é garantido ao escolar construir uma visão ampla do conceito de saúde (BRASIL, 1998). Sendo assim, se todos os professores em suas respectivas disciplinas abordassem as questões de saúde de forma mais expressiva, seria possivel que os alunos desenvolvessem uma visão mais ampliada das questões de saúde.

Contudo, é importante destacar algumas barreiras que podem implicar na dificuldade do trabalho transversal de saúde na escola, conforme apontam Silva et al. (2017). Os autores buscaram analisar as concepções de professores sobre os processos de Educação em Saúde no contexto escolar, bem como as principais dificuldades encontradas por eles para trabalhar o tema saúde no cotidiano escolar. Assim, encontraram que a maioria dos professores concorda que é de responsabilidade de todos abordarem o tema Saúde na escola. Porém, os mesmos reiteram que precisam de formação continuada e de material didático de qualidade a fim de dar-lhes suporte para realizar esse trabalho.

Desta forma, fomentar estratégias de formação inicial e continuada em saúde, voltadas aos professores das diferentes áreas do saber, seria uma alternativa importante para que o trabalho em saúde na escola acontecesse de forma mais significativa. Prochnow, Souza e Farias (2016), consideram as práticas educativas de extrema importância, pois facilitam trocas e construção Interfaces da Educ., Paranaíba, v.11, n.31, p. 501 - 524, 2020 
Percepções de estudantes em saúde...

de conhecimento entre professores profissionais de saúde e comunidade escolar. Os autores reforçam a necessidade da formação continuada como contribuição na formação global e holística e a abrangência no processo de promoção de saúde escolar.

\section{Considerações finais}

Podemos concluir que, independente da instituição avaliada, os escolares ainda apresentam uma visão limitada de saúde. Os alunos referem que na escola, os temas mais retratados versam sobre questões de "Higiene/Auto-cuidado" e "Aprendizagem sobre doenças/prevenção de doenças". Os mesmos apontaram ainda que, as disciplinas de Ciências e de Educação Física, são as áreas que mais trabalharam as temáticas de saúde.

Buscando encontrar possiveis associações entre o conhecimento desses escolares e o que é previsto no PPP escolar, observou-se que na escola A, diferentemente das outras escolas investigadas, os estudantes descreveram um conceito mais ampliado de saúde. Nesta escola, o conceito de saúde apresentado foi o mais próximo ao conceito previsto pela OMS, considerando que saúde não se refere apenas à ausência de doenças. Ademais, os estudantes também apresentaram percepções de saúde voltadas a questão mais biológica, envolvendo o funcionamento do corpo humano, indo ao encontro ao que é proposto no PPP da escola.

Ao verificar as respostas dos alunos da escola $B$, conclui-se que a vulnerabilidade social presente nessa comunidade escolar justifica a ênfase dada por eles aos temas "Questões sobre alimentação" e "Prevenção de DST e orientações sexuais". Um aspecto curioso é que, mesmo que o PPP desta escola não faça nenhuma referência a documentos como os PCN e a BNCC, a escola considera o contexto e as demandas de sua comunidade. Em relação à escola $\mathrm{C}$, apesar de tratar o tema saúde em seu PPP, fazendo referência à BNCC, os alunos não apresentaram uma percepção mais ampliada de saúde, relacionada a aspectos de promoção de saúde, prevista neste documento.

Com base no conhecimento das percepções dos escolares e da associação com o que é previsto no PPP de cada escola, foi possivel encontrar que, apesar de as escolas preverem a abordagem da temática saúde em seu Interfaces da Educ., Paranaíba, v.11, n.31, p. 501 - 524, 2020 
PPP, as percepções dos escolares sobre essa temática ainda são limitadas. Por esta razão, existe a necessidade da criação de estratégias efetivas para suprir as falhas encontradas.

Como contribuições, esse estudo aponta a relevância de o tema saúde ser trabalhado de forma significativa, tornando o aluno sujeito crítico e reflexivo. Ainda, sugere que o aluno seja capaz de tomar suas próprias decisões perante sua própria saúde e reconhecer os motivos pelos quais tomou determinadas decisões.

Em conclusão, reforçamos a necessidade de ações relacionadas à formação continuada dos professores, a fim de que se sintam capazes e preparados para trabalhar saúde de maneira efetiva na sala de aula. Observase a necessidade de estudos de prosseguimento, intentando uma apropriação destes professores em temáticas de saúde, por meio de formações que sejam bem estruturadas e com objetivos bem definidos. Desta forma, acredita-se que estas formações sejam positivas e que capacitem efetivamente os professores a fim de que a temática saúde seja abordada de uma forma mais abrangente no ambiente escolar, em sua visão global.

\section{REFERÊNCIAS}

BARBI, J. S; NETO, J. M. A Saúde nos anos finais do Ensino Fundamental:Uma análise de documentos de referência. Educação em Saúde e Educação em Ciências. XI Encontro Nacional de Pesquisa em Educação em Ciências - XI ENPEC Universidade Federal de Santa Catarina, Florianópolis, 2017.

BARDIN, L. Análise de conteúdo. Lisboa: Edições 70, 2006.

BORGES, T. et al. Conhecimento para fatores de risco sobre doenças crônicas: estudo de bases populacional. Cadernos Saúde Pública. Rio de Janeiro, 2009.

BRASIL. Base Nacional Comum Curricular (BNCC). Segunda versão revista. Brasília, MEC/CONSED/UNDIME, 2016. Disponivel em: http://historiadabncc.mec.gov.br/documentos/bncc-2versao.revista.pdf . Acesso em: 06/09/2019. 
Percepções de estudantes em saúde...

BRASIL.. Base Nacional Comum Curricular. Ministério da Educação. Brasília,' 2017. Disponível em: http://basenacionalcomum.mec.gov.br/. Acesso em $15 / 11 / 2018$.

BRASIL. Base Nacional Comum Curricular. Ministério da Educação. Brasília, 2017. Disponivel em: http://basenacionalcomum.mec.gov.br/. Acesso em $15 / 11 / 2018$.

BRASIL. Secretaria de Educação Fundamental. Parâmetros curriculares nacionais : terceiro e quarto ciclos: apresentação dos temas transversais / Secretaria de Educação Fundamental. - Brasília : MEC/SEF, 1998.

CZERESNIA, D. O conceito de saúde e a diferença entre prevenção e promoção. In: CZERESNIA, D.; FREITAS, CM (org.). Promoção da Saúde: conceitos, reflexões, tendências. 2 ed. ver. E ampl. Rio de Janeiro: Ed. Fiocruz, 2009.

DIAS, M. et al. Intersetorialidade e Estratégia Saúde da Família: tudo ou quase nada a ver?. Ciência \& Saúde Coletiva, v. 19, n. 11, p. 4371-4382, 2014.

GADOTTI, M. O Projeto Político-Pedagógico da escola na perspectiva de uma educação para a cidadania. Transcrição do debate realizado na Conferência Nacional de Educação para todos. Brasília, 1994.

LONGHI, S.; BENTO, K. Projeto Politico Pedagógico: Uma construção coletiva. Revista de divulgação técnico-científica do ICPG, v. 3, n. 9, 2006.

MACEDO, E.; CONCEIÇÃO, M. I. Significações sobre Adolescência e Saúde entre Participantes de um Grupo Educativo de Adolescentes. Psicologia: ciência e profissão, 2015, v. 35, n. 4, p. 1059-1073.

MACENA, R.H.M. Tendências pedagógicas e Educação em Saúde. Anima, v. 1, n. 5, p. 29-36, 2002.

MATOS, D.A.S; JARDILINO, J.R.L. Os conceitos de concepção, percepção, representação e crença no campo educacional: similaridades, diferenças e 
implicações para a pesquisa. Educação \& Formação, Fortaleza, v. 1, n. 3, p.' 20-31, 2016.

MCNAUGHT, C; LAM, P. Using wordle as a supplementary research tool. The Qualitative Report, v. 15, n. 3, p. 630-643, 2010.

MENDES, E. A construção do projeto politico curricular na escola "Severiano Marques" na comunidade Sitio Verdes em Queimadas-PB: desafios e conquistas durante o percurso. João Pessoa: UFPB, 2017.

MONTEIRO, P. H. A saúde nos livros didáticos no Brasil: concepções e tendências nos anos iniciais do Ensino Fundamental. Faculdade de Educação da Universidade de São Paulo. São Paulo, 2012.

MOREIRA, P.L.; DUPAS, G. Significado de saúde e de doença na percepção da criança. Rev Latino-am Enfermagem, v. 11, n. 6, p. 757-62, 2003.

NASCIMENTO, C. SCHETINGER, M. R. Folder educativo como estratégia de promoção e prevenção em Saúde mental: possibilidades teórico-metodológicas. Interfaces da Educ., Paranaíba, v.7, n. 20, p.195-210, 2016.

NEVES, R.A.; DAMIANI, M. F. Vygotsky e as teorias da aprendizagem. UNIrevista, v. 1, n. 2, 2006.

ORGANIZAÇÃO MUNDIAL DA SAÚDE. Carta da Organização Mundial de Saúde, 1946. Disponivel em http:// www.onuportugal.pt/oms.doc. Acesso em: $18 / 10 / 2019$.

PROCHNOW, T. R; SOUZA, M. L; FARIAS, M. E. Diagnóstico parcial das ações desenvolvidas para Educação em Saúde no Ensino Público em Boa Vista/Roraima/BR. Interfaces da Educ., Paranaíba, v.7, n.21, p.7-22, 2016.

SILVA, R. et al. Concepções de Professores Sobre os Processos de Educação em Saúde no Contexto Escolar. Contexto \& Educação. Editora Unijuí, v. 32, n. 103, 2017. 
Percepções de estudantes em saúde...

SOBRINHO, R. S. et al. Percepções dos profissionais da Educação e Saúde sobre o Programa Saúde na Escola. Revista Pesquisa Qualitativa. São Paulo (SP), v. 5, n. 7, p. 93-108, 2017.

VIERO, V. S. et al. Educação em saúde com adolescentes: análise da aquisição de conhecimentos sobre temas de saúde. Esc Anna Nery, v. 19, n. 3, p. 484-4, 2015.

WEYH, C. B. et al. A Dimensão do coletivo na construção do Projeto Politico Pedagógico. Revista DI@LOGUS. Cruz Alta, v. 8, n. 2, p. 24-35, 2019.

WORLD HEALTH ORGANIZATION. Health Promotion 2010. Disponivel em: https://www.who.int/healthpromotion/en/ Acesso em: 14/10/2019. 